Caries Res 1990;24(suppl 1):2

\title{
Changes in Diet and Caries Prevalence
}

Members of Workshop A

Prof. E. Newbrun

Chairman, University of California, San Francisco, Calif., USA

Prof. B. Angmar-Manson Raporteur, Karolinska Institute, Stockholm, Sweden

Prof. T. Marthaler

Presenter, Institut de Médecine Dentaire, Zurich, Switzerland

Mr. M. Midda Dental School, University of Bristol,

England

Dr. M. Miller Dental Resource Center, Princeton,

N.J., USA

Dr. S.J. Moss New York University, New York, USA

Prof. A. Thylstrup Royal Dental College, Copenhagen,

Denmark

Miss L. Stevens London, England

Opening Plenary Session

Participants

Prof. J. Banoczy

Dr. J.A. Beeley

Dr. B. Blot Mr. S. Buckley

Dr. H. Chauncey

Dr. J. De Soet Mr. R. Duckworth

Prof. W.M. Edgar

Dr. R. Feller

Dr. J. Harland

Dr. J. McEwan

Semmelweis Medical University,

Budapest, Hungary

Dental School, University of Glasgow,

Scotland

Roquette Frères, Paris, France

Ethical Communications, London,

England

US Veterans Administration, Boston,

Mass., USA

ACTA, Amsterdam, The Netherlands

Unilever Dental Research, Bebbington,

England

University Dental School, Liverpool, 


\section{England}

Veterans Administration Hospital,

Loma Linda, Calif., USA

British Sugar PLC, Peterborough,

England

Witwatersrand University,

Johannesburg, South Africa

Prof. Curzon: Ladies and gentlemen, may I welcome you to the opening session of the European

Conference on Diet, Nutrition and Dental Caries. Unfortunately due to a bereavement in his family Prof. Klaus König has not been able to come to this meeting. At very short notice, Prof. Newbrun has agreed to take over the chairmanship of the first session for us. Prof. Newbrun from the University of San Francisco needs little introduction as I am sure many of you are fully aware of his background in the area of caries research as he is the author of the definitive book on Cariology and has carried out extensive research.

Prof. Newbrun: Thank you, Prof. Curzon, and welcome. Certainly for me it is the first time I have had the opportunity to visit York, a beautiful historic city, and we look forward to the hospitality, ceremonies and social aspects of the conference as well as the scientific meeting that you have arranged for us.

The first speaker in the symposium is presenting a paper on a topic that I think has engendered a lot of discussion and speculation in the literature and that is 'Changes in the Prevalence of Dental Caries: How Much Can Be Attributed to Changes in Diet?' Prof. Tommy Marthaler of the Institut de Médecine Dentaire, Zurich, needs very little introduction as he is one of the leaders in biostatis-tical research in dentistry and certainly in the introduction and study of efficacy of preventative programs. 